patients will inevitably make further demands on our overstretched geriatric services. The long-term care of such patients in an acute ward-because they have nowhere else to go-will eventually reduce the capacity of the Service to treat those patients with cancer who are the most likely to benefit. The signs are very clear that this problem will get worse. Has the new triple-tiered administration got its plans well laid to cope with this threat? Otherwise, it could be a major bottleneck in the efficient running of services designed to provide active treatment of cancer.

1 Belcher, J R, British fournal of Diseases of the Chest, 1975, 69, 247.

2 Springett, V H, Thorax, 1966, 21, 132.

${ }^{3}$ Langston, H T, fournal of Thoracic and Cardiovascular Surgery, 1972, 63, 412 .

${ }^{4}$ Clemmesen, J, Danish Medical Bulletin, 1954, 1, 37.

5 Doll, R, Fournal of the Royal Statistical Society (series A), 1970, 134, 133.

${ }^{6}$ Day, $\mathrm{N}$ E, and Muir, C S, in Modern Trends in Oncology-1, ed R W Raven, p 29. London, Butterworths, 1973.

Clemmesen, J, Acta Pathologica et Microbiologica Scandinavica (section A), 1974, suppl No 247.

\section{Playing with genes}

In playing with genes, are we playing with fire ? In two previous leading articles ${ }^{12}$ we summarised the possible benefits and risks that may arise from snipping genes from virtually any organism and inserting them for rapid replication into a virus or bacterium - a process known as cloning. We also welcomed the voluntary moratorium on the possibly most dangerous kinds of experiment that had been advocated and accepted for themselves by the distinguished scientists of a committee of the National Academy of Sciences, led by Paul Berg of Stanford University. Broadly, the possible benefits of such manipulation of genes include an increase of fundamental knowledge about genes; correcting deficiency diseases; saving nitrogen fertilisers; and disposing of oil spills. The possible dangers include the creation and dissemination of novel epidemics and the introduction of cancer-causing genes into Escherichia coli, the micro-organism most widely used for genetic manipulations and a normal inhabitant of the human intestine.

In February 1975 some 140 geneticists from various countries met at Asilomar, California, to discuss the problems and recommend some guidelines. A valuable report in Nature ${ }^{3}$ gives an account of the essentials of this conference and of later discussions at Woods Hole in July 1975 and at La Jolla early in December 1975.

At Asilomar there was pressure to lift the voluntary moratorium, but there were also countervailing, well-justified fears that conventional laboratory safety procedures might not prevent viruses or bacteria with transplanted genes from escaping into the general community. The conference recommended that potentially hazardous experiments should be carried out only with viruses or bacteria so crippled that they could not survive outside a laboratory. Nevertheless, efforts to produce such crippled strains had taken much longer than expected; and an advisory committee of the US National Institutes of Health (NIH) met at Woods Hole in July 1975 to consider more stringent controls that had been recommended to meet the Asilomar guidelines without the hoped-for availability of these crippled strains. The Woods Hole conference was under considerable pressure, since there were warnings that the voluntary moratorium would not hold much longer, and its draft report provoked severe criticism because of weak- nesses at certain key points. When the NIH committee met at La Jolla in December 1975 it considered a much stronger revised draft, and after serious debate tightened the proposed regulations, consistently leaning in favour of more rather than less stringent precautions where there seemed to be options. The crucial factor was seen to be the need for the scientific community to be strict enough in its safety precautions to forestall the danger of legislation-which might seriously impair academic freedom.

Happily, a genetically crippled strain of $E$ coli $\mathrm{K} 12$ and at least two crippled strains of bacteriophage lambda have now appeared, and the results of preliminary tests encourage the hope that further rigorous examination will confirm that these micro-organisms will indeed provide a high degree of safety. The NIH committee emphasised the need to outlaw permanently certain experiments with highly pathogenic organisms and dangerous toxins, and it defined four levels of physical containment and three of biological containment and assigned various less dangerous proposed types of experiment to combinations of these two forms of containment. The committee's proposals are tabulated in detail in the report in Nature. ${ }^{3}$ The final official report is expected soon, and its recommendations will then go to the Director of NIH, who will probably accept them, and eventually they will be used in awarding grants for research. Nevertheless, it seems certain that these recommendations-which appear to be both sensible and sufficient-will also exert great influence throughout the scientific world, not least in Britain, where consideration is being given to the drafting of appropriate regulations to increase laboratory safety in general and in particular to deal with the procedures in genetic engineering.

\footnotetext{
1 British Medical fournal, 1974, 3, 483.

2 British Medical fournal, 1975, 1, 234.

N Nature, 1975, 258, 861 .
}

\section{Peripartum cardiac failure}

Unexpected heart failure in the puerperium or late in pregnancy has long been recognised ${ }^{1}$ and was included in Meigs's textbook ${ }^{2}$ in 1848 . When a myocardial disorder of mysterious cause presents within three months of childbirth the condition is usually labelled peripartum cardiac failure (PPCF) or peripartum cardiomyopathy. We still do not know whether the pregnancy has a specific aetiological role or is merely a non-specific haemodynamic stress in the course of preexisting subclinical heart muscle disease-which in the absence of pregnancy might not have been discovered or caused symptoms for many years, if ever.

The usual story ${ }^{3-15}$ is one of heart failure presenting with shortness of breath, palpitations, oedema, embolism, or, rarely, acute pulmonary oedema. Precordial discomfort resembling angina may occasionally lead to detection of the heart disorder. ${ }^{16}$ In other patients either pulmonary or, less often, systemic embolism may be the first clinical event. Diastolic hypertension has been described frequently, and systolic hypertension less often. ${ }^{15}$ Cardiac examination shows an enlarged left ventricle with a 3rd heart sound gallop and either no murmurs or a soft mitral systolic murmur associated with the left ventricular dilatation. When there is close cardiac surveillance a symptomless cardiomegaly or abnormal electrocardiogram may be the only abnormal feature in an apparently well woman. ${ }^{15}$ 